Preprint version of:

"A Method for Analysing the Gas Phase in Polyurethane Foam", M Svanström, O Ramnäs, J Cellular Plastics, 31:375-388, 1995.

DOI: $10.1177 / 0021955 X 9503100405$ 


\title{
ABSTRACT
}

\section{A METHOD FOR ANALYSING THE GAS PHASE IN POLYURETHANE FOAM}

\author{
M. Svanström and O. Ramnäs \\ Chalmers University of Technology, Sweden
}

A method for analysing the gas phase in polyurethane foam is described. The gas content of the foam sample is released by grinding in a special sampling equipment made from a metal pipe. The grinding is effected by pressing the cylindrical sample towards a rotating edge at the end of the pipe. The gas released during grinding is collected in a glass syringe, permitting the total gas volume to be determined. The syringe is connected to two gas sampling valves of a gas chromatograph. In the chromatograph, the gas is analysed on two different columns. For the qualitative analysis of samples with unknown gases and for the identification of impurities, a gas chromatograph - mass spectrometer system is used. Since the sampling equipment, with the sample inserted, is flushed with an inert gas before grinding, the "true" volume of the sample can be determined and the pressure in the cells can be calculated.

Key words: Polyurethane foam, cell gas, blowing agent, analysis, gas chromatography 


\title{
A Method for Analysing the Gas Phase in Polyurethane Foam
}

\author{
Magdalena Svanström and Olle Ramnäs* \\ Department of Chemical Environmental Science \\ Chalmers University of Technology \\ S-412 96 Göteborg, Sweden
}

\section{INTRODUCTION}

The insulative properties of a polymer foam depend upon the properties of the polymer, such as cell size, density and number of closed cells, and upon the thermal conductivities of the captive cell gases. The blowing agents tend to diffuse out of and air into the foam. This diffusion leads to a change in the cell gas composition over time and a continuous increase in the thermal conductivity. It is consequently of interest to determine the cell gas composition of a foam at different times. Quantitative analyses of the cell gases can be used to study the ageing behaviour of a foam, to determine diffusion coefficients for different gases and to calculate the thermal conductivity of the foam.

The total amount of blowing agents and other gaseous compounds in a foam is the sum of all gases in the cells and all blowing agents and other gaseous compounds dissolved in the solid polymer. The blowing agents and other gaseous compounds of interest are:

- Inorganic gases:

- Halocarbons:

- Hydrocarbons:

- Other organic compounds: Esters, fluorinated ethers etc.

Different methods have been used to determine the amount of blowing agents and other gaseous compounds present in a polymer foam. The total amount of halocarbons in the foam has been determined by incineration and absorption of the incineration products in an aqueous solution, followed by either titration for chloride and flouride or measurement with an ion-selective electrode (Ref. 1-7). A method using methanol to dissolve the blowing agents in the foam and a subsequent gas chromatographic analysis of the methanol solution has also been described (5). If the foam is heated 
to $350^{\circ} \mathrm{C}$, all the amounts of the blowing agents are released to the head space which can then be analysed by gas chromatography (5). The amount of halocarbons in a foam has been determined by X-ray flourescense $(6,7)$.

If the cell structure is destroyed and thereby the cell gases removed, the same methods as mentioned above can be used for the quantitative determination of blowing agents dissolved in the solid polymer $(8,9)$. In some methods, the amounts of blowing agents have been determined by weight loss measurements.

Different methods have been described for the determination of the cell gas composition. The sampling methods vary but gas chromatography has generally been used for the analysis. In one method, mass spectrometry was used (8). A syringe was used to take out small volumes of cell gases in one of the methods described (1). Since the concentration may be different in different parts of the foam, this method is only used for qualitative determination. For this purpose, the use of leak test instruments and infrared spectroscopy has also been described $(10,11)$. In order to collect the gas phases from a large number of cells, the cell structure must be destroyed. This has been effected by crushing the foam in a gasbag using a hydraulic press $(6,7)$ or by first cooling the sample in liquid nitrogen and then crushing the brittle foam $(8,9,12,13)$.

In the present work, a sampling method where the cell gases are obtained by grinding the foam is described. Initially, a sampling method similar to that suggested by du Cauze de Nazelle $(14,15,16)$ was used. The gas phase was then collected when the foam was simultaneously twisted and compressed. When the pressure is high, an increased amount of blowing agents may dissolve in the solid polymer. In order to eliminate this risk, the "grinder" method was developed.

\section{EXPERIMENTAL}

\section{Sampling}

A sample cylinder (diameter $=20 \mathrm{~mm}$, length $=60 \mathrm{~mm}$ ) is cut from the foam with a thin-walled metal pipe with a sharpened end. Care is taken to minimize the layer of destroyed cells. Then the sample is placed in the "grinder" and the system is flushed with dinitrogen oxide during 10 minutes in order to remove all oxygen and nitrogen in the gas phase surrounding the sample. Dinitrogen oxide was chosen because it is not used in foams and does not interfere with the other gaseous components in the chromatographic analysis. 
The cell gases of the foam sample are released by grinding in a special sampling equipment made from a metal pipe (Figure 1). The grinding is carried out by pressing the cylindrical sample towards a rapidly rotating edge at the end of the pipe. The edge is a lathe steel attached to a shaft on bearings. The rotation is effected by a simple electric drill with variable speed. The grinding normally takes less than 20 seconds. The sample is attached to the metal piston by small wooden sticks, allowing all the sample to be grinded without destroying the rotating edge.

The gas released during grinding is collected in an all-glass syringe permitting the total gas volume to be determined. Since it is not possible to transfer the whole gas sample to the syringe in this case (because of the edge), it is important that all the collected gas is thoroughly mixed. This is done by pushing the piston of the grinder backwards and forwards (about $2 \mathrm{~cm}$ ) two times.

The syringe is connected to the gas sampling valve of a gas chromatograph. The chromatographic analysis is performed as soon as all the gas is collected and thoroughly mixed.

The small particles formed during grinding partially block a filter at the beginning of the tube leading to the glass syringe. In order not to build up too high a gas flow resistance, the particles in the filter must be rinsed away by backflushing with methanol. For some types of foam it is necesssary to rinse after each grinding.

\section{Gas chromatography}

It is difficult to separate compounds with very different molecular masses, e.g. permanent gases and heavy CFCs, on one gas chromatographic column. In this case two columns were used, one with a molecular sieve and one with a porous polymer as the stationary phase. As shown in Figure 2, the columns were connected to the two inlets (sample and reference gas, respectively) of a thermal conductivity detector $\left(150 \mathrm{~mA}, 200^{\circ} \mathrm{C}\right)$ in the gas chromatograph (Perkin Elmer 3920B). Helium was used as a carrier gas (25 ml/min).

The analysis has to be performed as soon as the gas sample is collected, because air will diffuse into, and the cell gases will diffuse out of the all-glass syringe. It is difficult to use a gas-tight syringe, because the piston is sluggish to push. In an all-glass syringe, the piston can be pushed very easily, permitting accurate determination of the total gas volume.

First the concentrations of oxygen and nitrogen are determined on the molecular sieve column at $80^{\circ} \mathrm{C}$. The chromatograhic analysis is fast, one analysis is completed in about 1 minute. Then the polarity of the detector is 
changed and the concentrations of carbon dioxide and dinitrogen oxide are determined on the porous polymer column, also at $80^{\circ} \mathrm{C}$. This analysis is completed in less than 2 minutes. The oven temperature is increased to $180^{\circ} \mathrm{C}$. When all compounds from earlier injections have been eluted (takes about 5 - 10 minutes), a final gas sample is injected on the porous polymer column for the determination of the concentration of halocarbons and hydrocarbons (CFC, HCFC, FC, HFC, HC etc).

A packed molecular sieve column (molecular sieve 13X, $170 \mathrm{~cm} \times 1 / 8 "$ ) was used for the separation of oxygen and nitrogen. Only permanent gases, like hydrogen, helium, neon, argon, oxygen, nitrogen, methane and carbon monoxide, can be separated on this column. No other gases than oxygen and nitrogen, and sometimes traces of methane, were seen on the chromatogram. About 0.05 vol\% oxygen or nitrogen can be detected in a gas sample $(290 \mu \mathrm{l})$.

A packed porous polymer column (HayeSep Q, $190 \mathrm{~cm} \mathrm{x} \mathrm{1/8")} \mathrm{was} \mathrm{used}$ for the separation of all compounds except oxygen and nitrogen. At $80^{\circ} \mathrm{C}$ and $180^{\circ} \mathrm{C}$, air (oxygen and nitrogen) appears as a single peak in the beginning of the chromatogram. At the lower temperature $\left(80^{\circ} \mathrm{C}\right)$, carbon dioxide and dinitrogen oxide are well separated. At the higher temperature $\left(180^{\circ} \mathrm{C}\right)$, all halocarbons and hydrocarbons of interest are eluted within 1 - 15 minutes. A disadvantage of most gas solid chromatography (GSC) columns is that the retention time varies with the amount of sample. A small amount gives the highest retention and the most symmetrical chromatographic peak.

For compounds with similar chemical structure, a relationship exists between the boiling point and the retention time on this type of chromatographic columns (Figure 3). This relationship is very helpful in the qualitative analysis, often permitting a preliminary identification of an unknown peak. This identification must always be confirmed by other methods (GC/MS, reference gases).

About $0.1-0.5 \%(\mathrm{v} / \mathrm{v})$ CFC can be detected in a gas sample $(190 \mu \mathrm{l})$. Early eluting compounds, corresponding to sharp chromatographic peaks, can be detected at lower concentrations than late eluting compounds giving broad peaks. If another detector (flame ionization detector or mass spectrometer) is used, the detection limit will be about 1000 times lower.

Water is found in small amounts, $0.2-2 \%(\mathrm{v} / \mathrm{v})$, in all samples. At $180^{\circ} \mathrm{C}$, water is eluted very early as a peak with severe tailing. Unfortunately, halocarbons with low boiling points are also eluted in this region. If they are present in small amounts, a quantitative analysis is impossible. The separation of these halocarbons is more favourable at a lower temperature $\left(120^{\circ} \mathrm{C}\right)$. 


\section{Gas chromatography - mass spectrometry}

The Varian Saturn II Ion Trap GC/MS system is used for the identification. The separations are made on a long, non-polar capillary column (DB-1, $60 \mathrm{~m} \times 0.25 \mathrm{~mm})$ with a thick layer of the stationary phase $(1 \mu \mathrm{m})$. The chromatographic and mass spectrometric conditions are described in Figure 4, which gives the total ion chromatogram from the separation of 19 halocarbons and hydrocarbons.

A small volume (10-20 $\mu \mathrm{l})$ of the gas sample from the grinder is injected splitless on the SPI-injector with a gas-tight $25 \mu 1$-syringe. Under the conditions used (with no preconcentration), it is possible to determine most halocarbons and other organic compounds present in concentrations of about $1 \mathrm{ppm}$ or higher.

The mass spectra of most halocarbons are very typical and suitable for structure determination. Most common halocarbons can be found in the mass spectral library (NIST).

\section{Calibration}

Calibration is simple for all gaseous compounds. The loop of the gas sampling valve is filled with a pure gas. For each column, the same loop is used all the time. The area of the chromatographic peak is determined by a Hewlett Packard 3394A Integrator. This area corresponds, of course, to $100 \%$, if no impurities are present. The concentration $(\%, v / v)$ of a compound in a gas sample is calculated by dividing the area of the compound in the sample by the area of the pure compound.

For liquid compounds, calibration mixtures must be prepared. An evacuated gas cylinder ( 1 liter) is connected to a tube (SS, 1/8") filled with a small amount $(1.000-2.000 \mathrm{~g})$ of the liquid. The amount of liquid evaporated into the gas cylinder is determined by weighing the cylinder before and after the evaporation. The cylinder is then connected to a large nitrogen cylinder, and nitrogen is added up to $1-5 \mathrm{MPa}$, depending on the risk of condensation of the compound. The amount of nitrogen is determined by weighing. From the weights, the concentration (mole fraction or \% by volume) of the compound in the gas cylinder can be calculated.

Since a gas sampling valve is used, repeated injections of pure substances result in areas varying less than $0.1 \%$. The calibration areas of most compounds are stable for long periods (months). While the calibration areas of all permanent gases have remained almost unchanged for 1 year, the areas of heavy halocarbons have decreased slowly all the time (about $30 \%$ in 1 year). The detector response is not linear for some compounds (e.g. 1,1,1-trichloroethane) at very high concentrations in the sample. 


\section{Calculation}

The cell gas pressure $(P)$ can be calculated from

$$
P=\left(V_{T O}-V_{N}\right) * 100 /\left[V_{S A} *\left(1-D_{F} / D_{P}\right)\right]
$$

where

$V_{T O}=$ total volume $\left(20^{\circ} \mathrm{C}, 100 \mathrm{kPa}\right)$ of gas in the system after grind ing $=$ volume of gas remaining in the grinder after grinding + the small volume of the connecting tube + the measured volume of the gas in the syringe.

$V_{N}=$ volume $\left(20^{\circ} \mathrm{C}, 100 \mathrm{kPa}\right)$ of dinitrogen oxide $=N * V_{T O} / 100$, where $N$ is the concentration (\%, v/v) of dinitrogen oxide determined by gas chromatography.

$V_{S A}=$ "true" volume of the sample $=$ total volume of all undestroyed cells + volume of the solid polymer framework. $V_{S A}$ can be calculated from $V_{S A}=V_{G R}-V_{N}$, where $V_{G R}$ is the volume of the empty grinder when the piston is pushed in as much as just before an analysis.

$D_{F}=$ density of the foam

$D_{P}=$ density of the solid polymer $=1200 \mathrm{~kg} \mathrm{~m}^{-3}$

\section{RESULTS AND DISCUSSION}

The quantitative determination of the gas phase in polyurethane foams includes two steps: sampling and gas chromatographic analysis. The sampling is much more difficult to perform correctly than the gas chromatographic analysis. The main problem is how to get a representative sample of the cell gas without influencing the equilibrium between the compounds in the gas phase and those dissolved in the solid polymer. A change in the pressure or the temperature will affect this equilibrium.

In methods where the foam is compressed during sampling, the amount of halocarbons in the polymer may increase because of the increased pressure, unless this increase is of a very short duration. In the grinding method, the pressure is not affected during sampling.

For some foams it was found that, if the pressure is too high during flushing with dinitrogen oxide, this gas will diffuse into the foam and too small a sample volume and consequently too high a cell gas pressure will be calculated. In order to control the pressure during flushing $(<10 \mathrm{~mm}$ water), a gas flow meter is connected to the grinder (see Figure 1).

It is important that the sampling does not give rise to an increased temperature. An increased temperature can be expected to give an increased amount of halocarbons in the gas phase because of higher vapour pressure and decreased solubility in the solid polymer. It is difficult to grind foams of high density $\left(>90 \mathrm{~kg} / \mathrm{m}^{3}\right)$. The procedure takes a long time and may lead to a rise in temperature. This can be avoided by taking shorter cylindrical samples, which can be grinded faster. 
If several sample cylinders are taken from the same part of a foam, the results of the analyses will normally differ less than $\pm 2 \%$ units for gases in the concentration range $10-100 \%(\mathrm{v} / \mathrm{v})$.

The method described in this work has been used in our laboratory for two years, mainly in a study on the diffusion of blowing agents in different types of polyurethane foams. The concentrations of all compounds in the gas phase are measured, and the total pressure and partial pressures are calculated. A typical example from this study is given in Figure 5. The changes in cell gas pressure and partial pressures over time are given for a $\mathrm{CFC}$ 11-blown foam. The pressures follow even curves, indicating that the analyses are reasonable. The ratio of oxygen to nitrogen diverged initially from that in air but seems to approach this value after more than 200 days.

\section{ACKNOWLEDGEMENT}

The authors are grateful to the National Swedish Board for Industrial and Technical Development for their financial support. 


\section{REFERENCES}

1. Lohmeyer, S. and G. Müller. 1970. Kältetechnik - Klimatisierung, 22:291-295.

2. Steinle, H. 1971. Prog. Refrig. Sci. Technol., Proc. 13th Int. Congr. Refrig., pp 47-52.

3. Lohmeyer, S. 1982. Gummi Asbest Kunststoffe, 35:66-70 and 202-204.

4. Wiedermann, R. E., Adam, N. and R. Kaufung. 1988. J. Thermal Insulation, 11:242-253.

5. Ascough, M. R. Int. Workshop on Long Term Thermal Performance of Cellular Plastics, Huntsville, Ontario, Canada, Sept. 28-29, 1989.

6. Wan, C., Tyler, F., Nienhuis, N. and R. Bell. 1991. J. Cellular Plastics, 27:163-175.

7. Wan, C., Tyler, F., Nienhuis, N. and R. Bell. Int. Workshop on Long Term Thermal Performance of Cellular Plastics, Huntsville, Ontario, Canada, Sept. 28-29, 1989.

8. Norton, F. J. 1967. J. Cellular Plastics, 3:12-26.

9. Brandreth, D. A. and H. G. Ingersoll. 1980. J. Cellular Plastics, 16:235-238.

10. Olsson, M., Månsson, M. and B. Lundgren. 1989. SP Report 1989:5 (in Swedish), Swedish National Testing and Research Institute.

11. Jacobsson, O., Månsson, M. and M. Olsson. 1990. SP Report 1990:46, Swedish National Testing and Research Institute.

12. Khalil, M. A. K. and R. A. Rasmussen. 1986. J. Air Pollution Control Association, 36:159-163.

13. Khalil, M. A. K. and R. A. Rasmussen. 1986. Advances in Foam Aging (Ed: D. A. Brandreth), pp 195-215, Yorklyn, DE: Caissa Editions.

14. Du Cauze de Nazelle, G. R. M., Bart, G. C. J., Damners, A. J. and A. Cunningham. Int. Workshop on Long Term Thermal Performance of Cellular Plastics, Huntsville, Ontario, Canada, Sept. 28-29, 1989. 
15. Cunningham, A., Sparrow, D. J., Rosbotham, I. D. and G. M. R. du Cauze de Nazelle. 32nd Annual Polyurethane Technical/Marketing Conference, pp 56-63, San Francisco, California, USA, Oct. 1-4, 1989.

16. Demonstration by du Cauze de Nazelle at a seminar (Thermal conductivity ageing of rigid polyurethane foams) at Delft University of Technology, Oct. 1990. 


\section{BIOGRAPHIES}

\section{O. Ramnäs}

Olle Ramnäs, $\mathrm{Ph}$. D., is an University Lecturer at the Department of Chemical Environmental Science, Chalmers University of Technology. During the last decade, his main research area has been the analysis of organic air pollutants. He is a member of an interdisciplinary research group at Chalmers University of Technology, working in the field of CFC-free polyurethane foam.

\section{Svanström}

Magdalena Svanström, M. S. (Chemical Engineering), is a Ph. D. student at the Department of Chemical Environmental Science, Chalmers University of Technology. She is a member of an interdisciplinary research group at Chalmers University of Technology, working in the field of CFC-free polyurethane foam. 


\section{LEGENDS}

Figure 1. The grinder.

Figure 2. The gas chromatograph and the sampling equipment (grinder and syringe) used for analysing the gas phase in polyurethane foam.

Figure 3. The boiling point of the compound analysed versus the corresponding retention time on the HayeSep Q-column (190 cm x 1/8", $\left.180^{\circ} \mathrm{C}, 25 \mathrm{ml} / \mathrm{min}\right)$.

Figure 4. Chromatographic separation of 19 halocarbons and hydrocarbons. The total ion GC/MS chromatogram is shown. Varian Saturn II GC/MS Ion Trap System, 30-200 m/e, 1 scan/s.

Column: DB1, $60 \mathrm{~m} \times 0.25 \mathrm{~mm}, \mathrm{df}=1.0 \mu \mathrm{m}$.

Temperature program: $-30^{\circ} \mathrm{C},+3^{\circ} \mathrm{C} / \mathrm{min}$.

Carrier gas: Helium, $25 \mathrm{~cm} / \mathrm{s}$.

Sample: $20 \mu 1$ gas mixture, SPI-injector.

Figure 5. The change in the total cell gas pressure (upper figure) and in the partial pressures of the cell gases (lower figure) over time in a CFC 11-blown polyurethane slab (thickness $30 \mathrm{~mm}$, density $48 \mathrm{~kg} / \mathrm{m}^{3}$ ) stored at room temperature. 


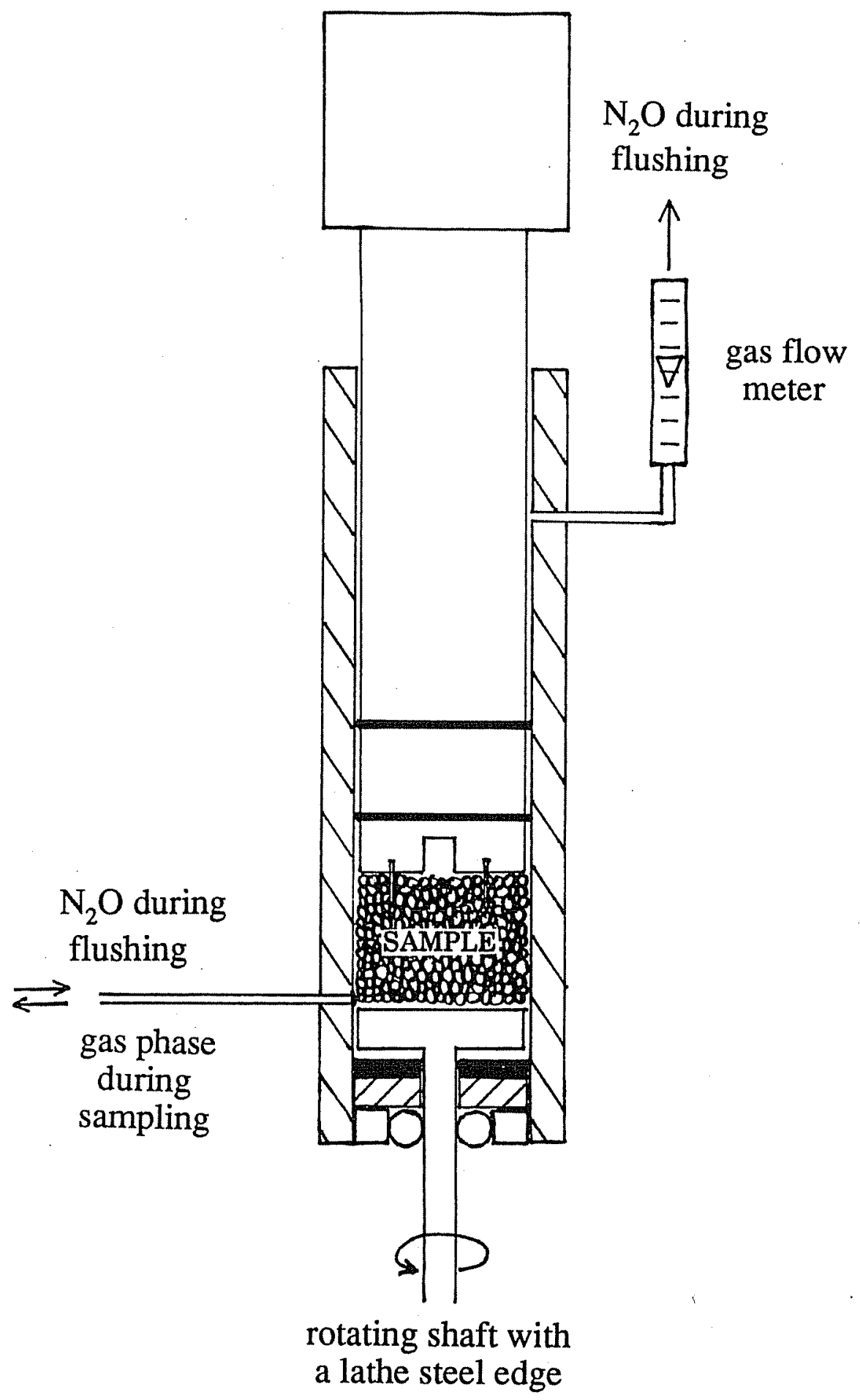

Figure 1. The grinder. 


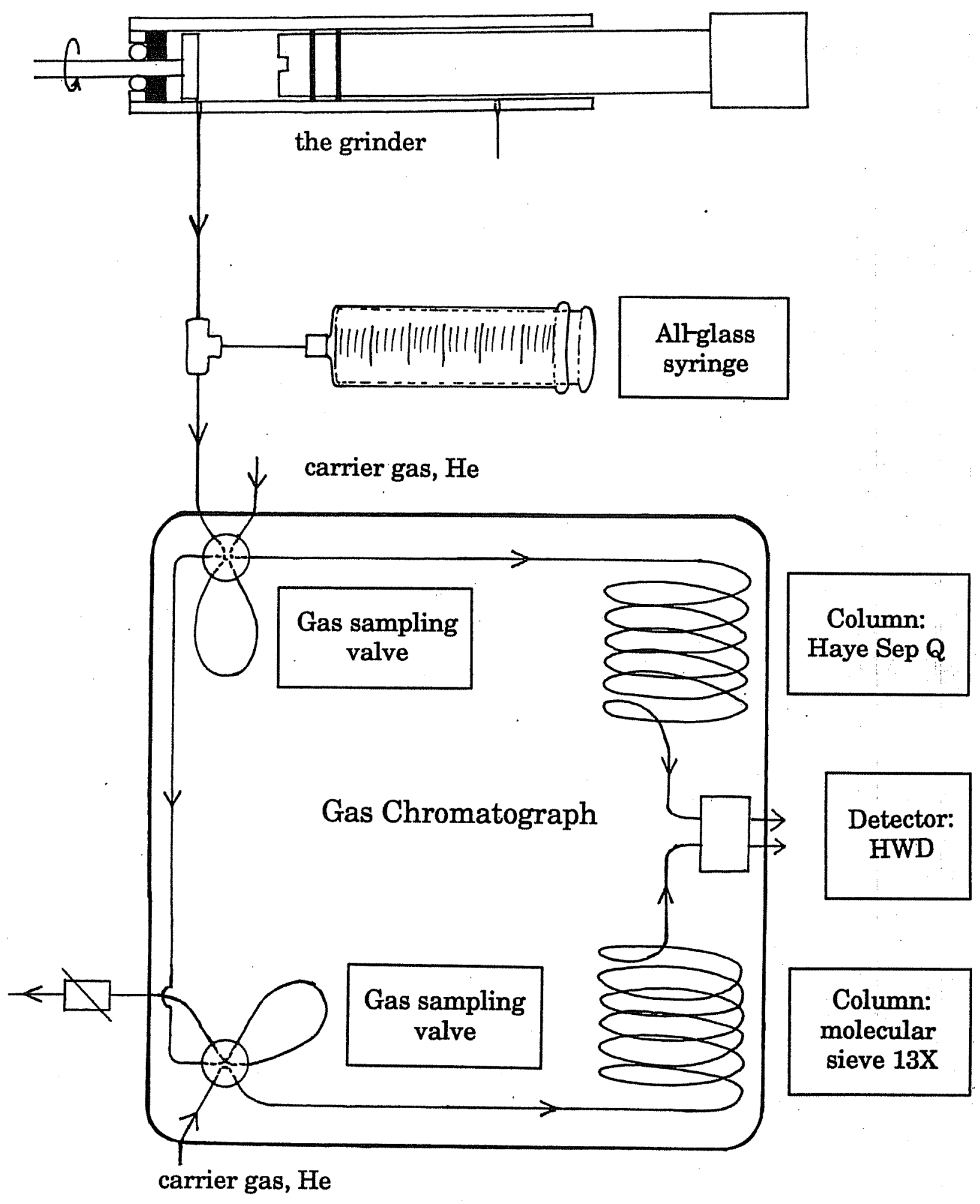

Figure 2. The gas chromatograph and the sampling equipment (grinder and syringe) used for analysing the gas phase in polyurethane foam. 


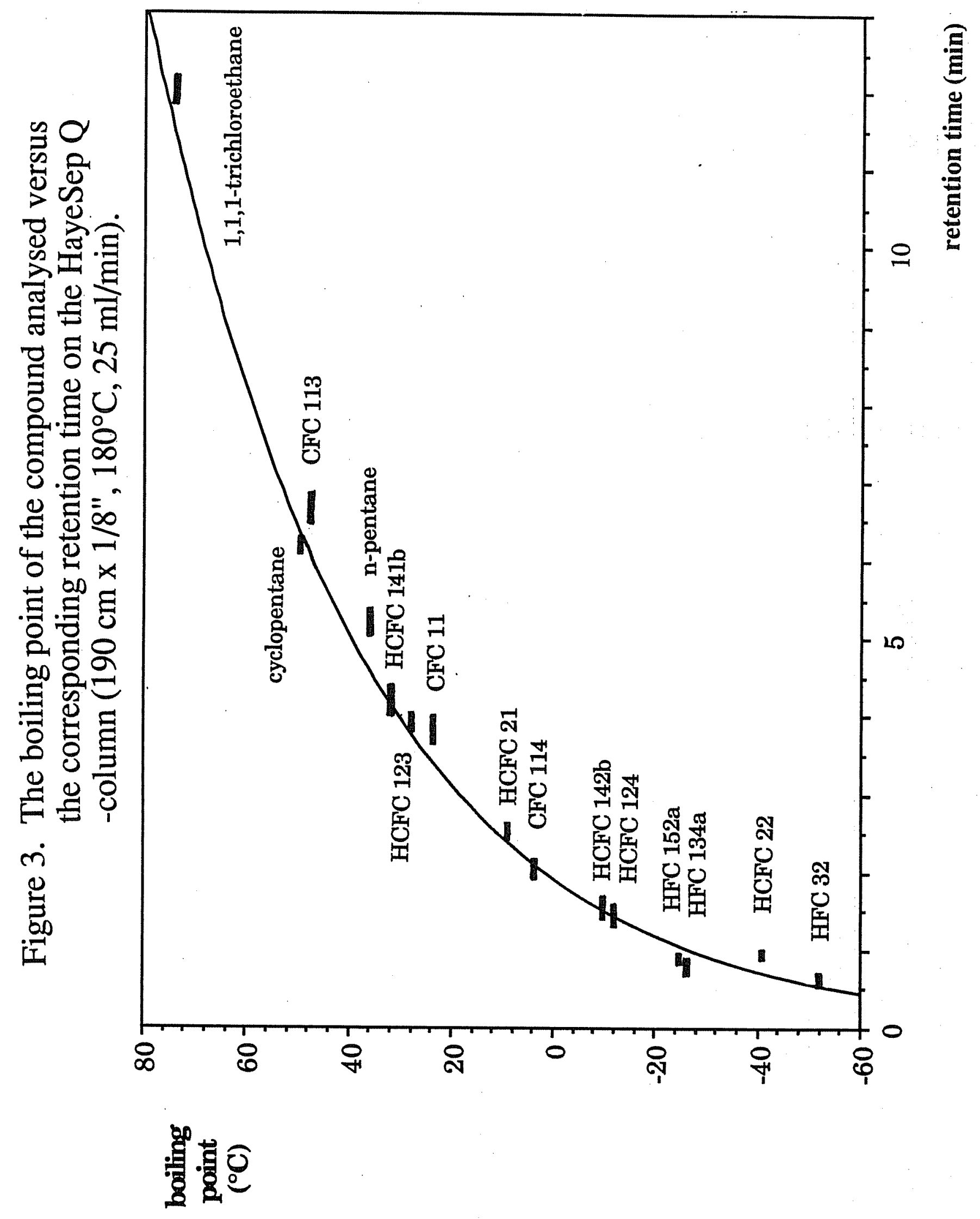



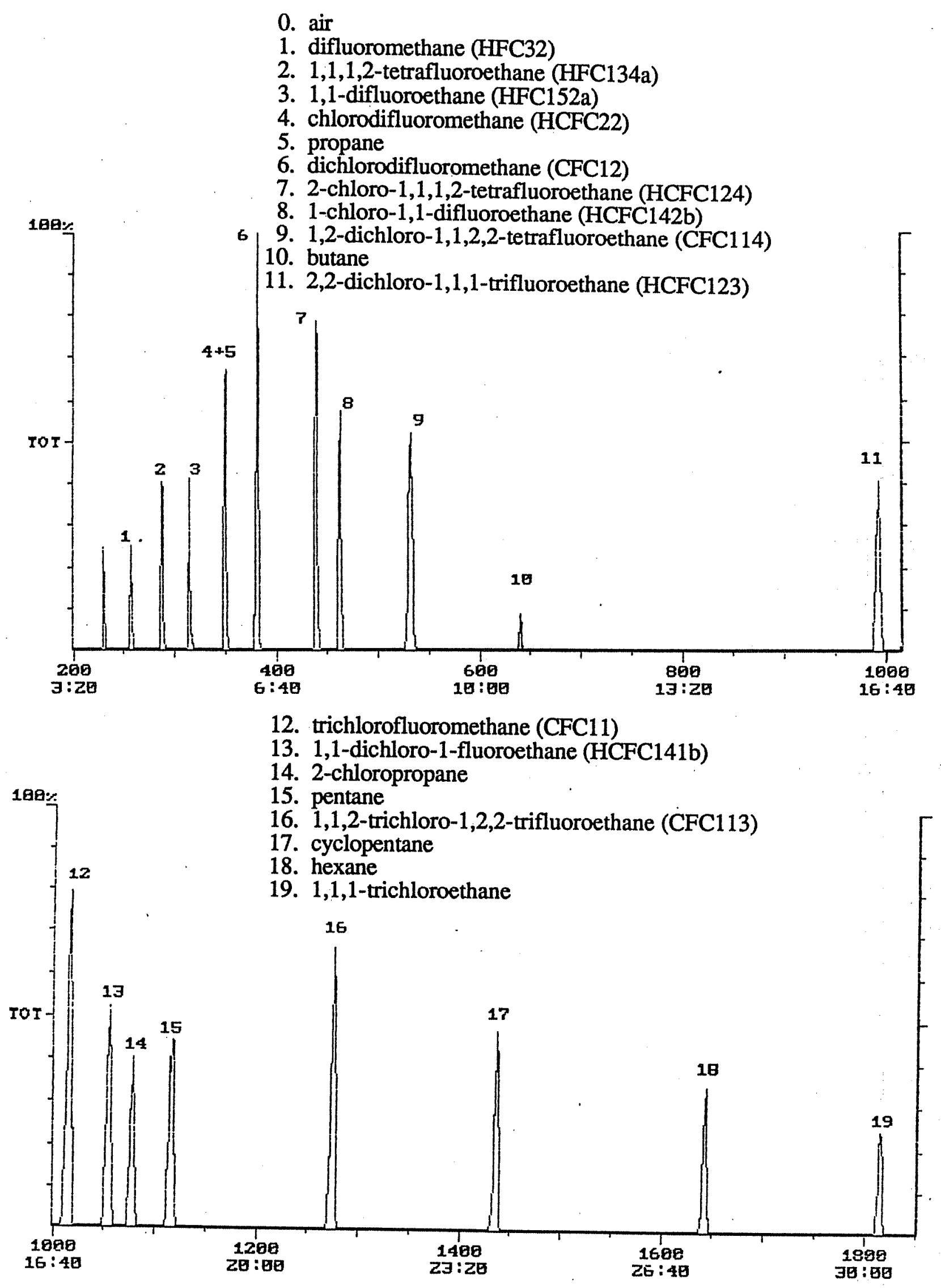

Figure 4. Chromatographic separation of 19 halocarbons and hydrocarbons. The total ion GC/MS chromatogram is shown. Varian Saturn II GC/MS Ion Trap System, 30-200 m/e, $1 \mathrm{scan} / \mathrm{s}$.

Column: DB1, $60 \mathrm{~m} \times 0.25 \mathrm{~mm}, \mathrm{df}=1.0 \mu \mathrm{m}$.

Temperature program: $-30^{\circ} \mathrm{C},+3^{\circ} \mathrm{C} / \mathrm{min}$.

Carrier gas: Helium, $25 \mathrm{~cm} / \mathrm{s}$.

Sample: $20 \mu 1$ gas mixture, SPI-injector. 


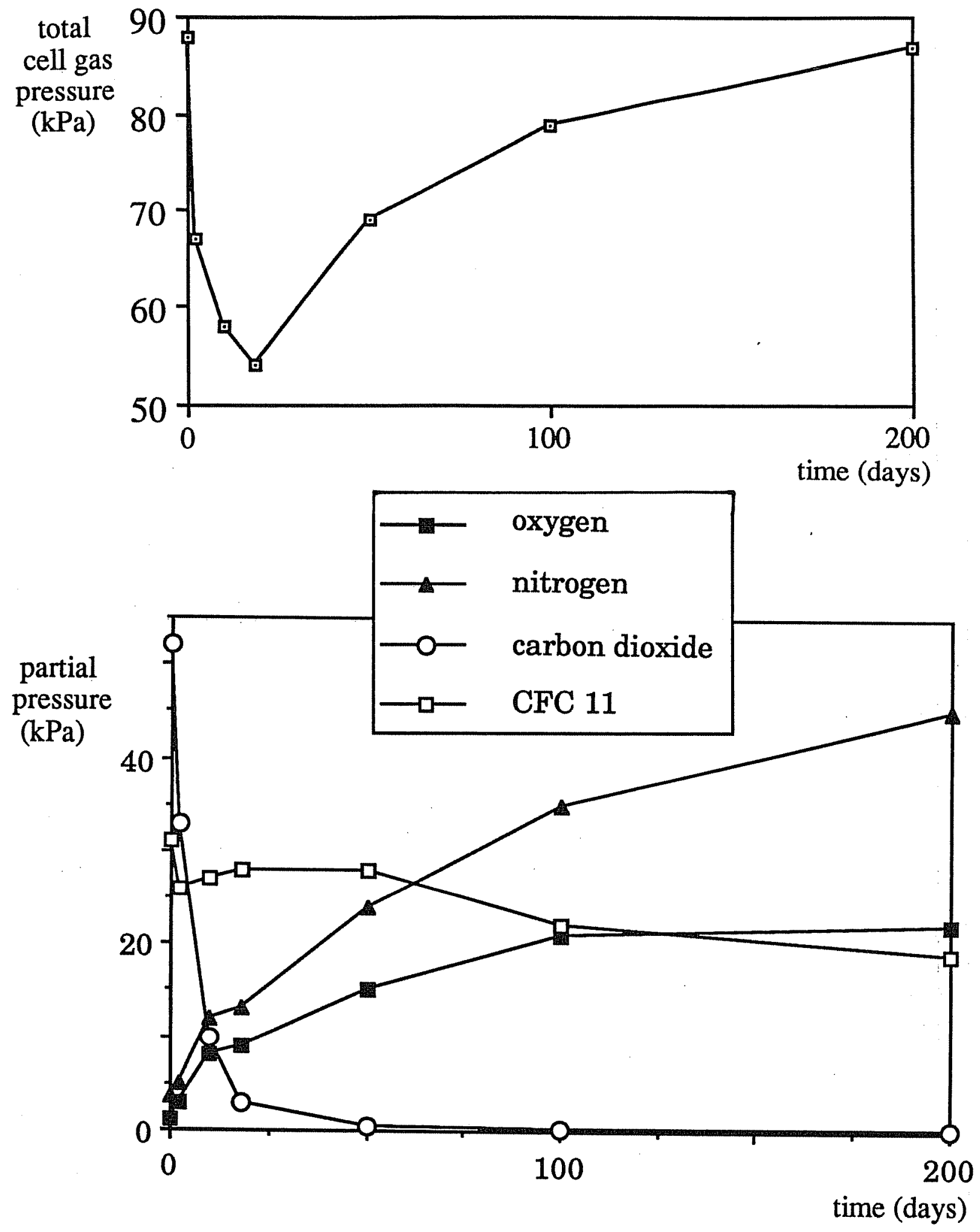

Figure 5. The change in the total cell gas pressure (upper figure) and in the partial pressures of the cell gases (lower figure) over time in a CFC 11-blown polyurethane slab (thickness $30 \mathrm{~mm}$, density $48 \mathrm{~kg} / \mathrm{m}^{3}$ ) stored at room temperature. 